\title{
Workload and Quality of Life of Medical Doctors in the Field of Oncology in Germany - a Survey of the Working Group Quality of Life of the AIO for the Study Group of Internal Oncology
}

\author{
Matthias Hipp ${ }^{a}$ Lothar Pilz ${ }^{b}$ Salah E. Al-Batran ${ }^{c}$ Matthias G. Hautmann ${ }^{a}$ \\ Ralf-Dieter Hofheinz ${ }^{d}$ \\ ${ }^{a}$ Klinik und Poliklinik für Strahlentherapie, Universitätsklinikum Regensburg, Germany; \\ ${ }^{b}$ Medizinische Fakultät Mannheim, Universität Heidelberg, Germany; \\ ${ }^{c}$ II. Medizinische Klinik für Hämatologie und Onkologie, Krankenhaus Nordwest, Frankfurt/M., Germany; \\ dIII. Medizinische Klinik für Hämatologie und Onkologie, Universitätsmedizin Mannheim, Germany
}

\section{Keywords}

Job stress · Job satisfaction · FBAS-questionnaire

\section{Summary}

Background: An increasing number of surveys have investigated professional stress and satisfaction among oncologists. Coevally, structural development has changed the oncological working environment. This survey investigated the quality of life and job stress among German oncological physicians. Methods: A 48-item questionnaire, which included the 'Stress questionnaire of physicians and nurses' (FBAS), was developed by the 'Quality of life' working group of the Internal oncology study group (AIO), and distributed anonymously at the annual meeting of the AIO working group in 2010. Descriptive statistics as well as univariate and multivariate analysis were performed. Results: 261 oncologists, mostly male $(64 \%)$, older than 40 years $(38 \%)$, and medical specialists $(78 \%)$, took part in the survey. 'Structural conditions' were identified as causing the highest mean stress levels, followed by 'professional and private life'. Female participants showed a significantly lower global quality of life than male participants $(p=0.020)$. 'Structural conditions' induced more stress among younger oncologists $<50$ years old $(p<0.001)$. Qualification status was influenced by gender $(p<0.001)$; the multivariate analysis described the dependence of gender ( $p=0.0045)$, working situation $(p=0.0317)$ and global stress $(p=0.0008)$. Conclusion: Structural conditions, age younger than 50 years and female gender were iden- tified as stress risk factors among the AlO members, and showed that job stress is present in German oncology. Further research is warranted to develop evidence-based intervention strategies.

\section{Background}

Since the 1990s professional stress and satisfaction has been investigated in an increasing number of surveys among physicians. In 1991, an early analysis among American oncologists was published dealing with the extent of burnout as the final result of stress, revealing that the incidence of burnout is dependent on the type of practice [1]. Whippen et al. identified frustration or a sense of failure as the most frequently chosen descriptions of burnout (56\%), and insufficient personal and/or vacation time the most frequent reason for burnout (57\%). There was a trend for the rate of frustration to be higher in physicians who had finished their professional training later. The highest rate of burnout was found among medical oncologists $(58 \%)$, radiation oncologists $(52 \%)$, and surgical oncologists (48\%).

Since 1991 the working environment in medicine and oncology has changed: the mean residence time of patients in hospitals is decreasing and coevally the workload is increasing for inpatient and ambulant therapies. Meanwhile, in Germany, the number of female physicians has risen generally and in oncological disciplines. Federal Medical Association (Bundesärztekammer) statistics reported an increase of females employed as medical oncologists

\section{KARGER}

Fax +497614520714

\section{(c) 2015 S. Karger GmbH, Freiburg}

2296-5270/15/0384-0154\$39.50/0 
from about 19\% in 1998 to $30 \%$ in 2011, and as radiation oncologists from $35 \%$ to $46 \%$, respectively [2].

A large survey among UK hospital consultants showed an increase of psychiatric morbidity from $27 \%$ in 1994 to $32 \%$ in 2002 and a parallel rise of emotional exhaustion from $32 \%$ to $41 \%$, especially for clinical and surgical oncologists [3]. In this investigation clinical and surgical oncologists were the only specialists to report rising job stress without a similar increase in job satisfaction. Another survey conducted by the Brazilian Society of Medical Oncology found the presence of burnout more frequently in younger oncologists (43.73 \pm 0.9245 vs. $35.87 \pm 3.1352 ; \mathrm{p}=0.018)$ [4]. A high prevalence of job stress for young physicians was also shown by Buddeberg-Fischer et al. [5], who described this as being caused particularly by an imbalance between workload and job satisfaction. As a consequence, in groups experiencing long-standing stress during postgraduate training, significantly worse health and life satisfaction are seen [6]. Probably the working environment in hospitals causes higher levels of working stress and burnout and lower job satisfaction than in private practice [7].

The current survey sought to investigate global quality of life (QoL), and job-associated stress of physicians working in the field of oncology according to age- and gender-specific differences.

\section{Methods}

\section{Questionnaires}

For the present study a 48-item questionnaire was used. The main part comprised the validated 42-item 'Stress questionnaire of physicians and nurses' (FBAS; 'Fragebogen zur Belastung von Ärzten und Schwestern') [8-12], which was applied with 6-step scale ('does not apply to me' (0), 'applies to me: only slight problem' (1) up to 'applies to me: a very big problem' (5)). Additionally, information was requested about: personal working qualification status (medical specialist/assistant); subject (4 oncological medical subjects: medical oncology, surgery, radio-oncology and 'other' with subdivisions of general medicine to hematology, gastroenterology, and pneumology); working situation (hospital, doctor's office, both and 'other'); gender; age (4 groups: < 30, 30-40, 41-50, $>50$ years); and a self-assessment of global QoL.

The study was developed and processed by the 'QoL and patient-reported outcome research' working group of the Internal oncology study group (Arbeitsgemeinschaft für Internistische Onkologie, AIO) of the German Cancer Society.

The FBAS questionnaire was evaluated following the Herschbach's description of a 6-degree scale of the 42 items, using 5 stress scales (scale 1: structural conditions - 10 items; scale 2: stress by compassion - 13 items; scale 3 : disagreeable patients -8 items; scale 4 : professional and private life -5 items; scale 5 : problems with colleagues -6 items) and additionally all items as a global stress score. Higher score levels are associated with higher stress.

For the self assessment of the global QoL, a continuous visual analogous scale between 0 and 10 was used, intermediate values were rounded to the given 11 categories.

\section{Recruiting Oncological Physicians}

The questionnaire was distributed among physicians participating at the annual meeting of the AIO working group in 2010, and via e-mail using the AIO member e-mail register. The physicians were asked to fill in the 3-page paper questionnaire anonymously.

\section{Data Analysis}

Returned questionnaires were collected in a database and statistically analyzed using Cytel Studio 9 (descriptive statistics and regression) and SAS 9.2 (boxplots, Wilcoxon-rank-sum tests and multiple tests). Significance level for multiple testing was corrected by the method of Bonferroni-Holmes.

For the variable 'qualification status' univariate analysis was performed using the grouping variables faculty, work situation, gender, and age group, respectively. The exact Fisher test was used for $\mathrm{p}$ values (for age groups the $\chi^{2}$-test is used for technical reasons). Multivariate analysis for the variable qualification status was done using a logistic regression model with the co-variables faculty, work situation, gender, and age group. For the latter model a goodness-of-fittest was conducted with a Hosmer-Lemeshow test supporting the model. Significance level was set to $\alpha=0.05$.

\section{Results}

\section{Participants' Characteristics}

Altogether 261 oncologists took part in the survey: 84 participants of the annual AIO-meeting and another 123 AIO members. Thus, the response rate was $14.5 \%$. Not all participants provided full information for every item. The majority of the participants were male ( $n=139 ; 64 \%)$, the minority female $(n=79 ; 36 \%) ; 43$ participants gave no gender information. Age was divided into 4 categories: < 30, 30-40, 41-50 and > 50 years. The majority were older than 40 years: 94 (38\%) between 40 and 50 years and 73 $(30 \%)>50$ years. Only 22 (9\%) were younger than 30 years and 58 (23\%) between 30 and 40; 14 gave no information about their age. Most of the physicians ( $\mathrm{n}=182 / 78 \%$ ) were medical specialists, only $52(22 \%)$ medical assistants and 27 did not answer this question. Most of participants $(n=255)$ declared their working situation with the following distribution: working in a hospital $\mathrm{n}=192$ (75\%), in a doctor's office $\mathrm{n}=43(17 \%)$, combined in both $\mathrm{n}=12$ (5\%), and in other institutions $n=8$ (3\%). 257 answers were registered for the subject of medical specialization in categories such as internal medicine (with additional subdivision in hematology-oncology, gastroenterology, pneumology), surgery, radio-oncology, and others. The majority were hematologists/oncologists ( $\mathrm{n}=177$; $69 \%)$ followed by internal specialists $(\mathrm{n}=38 ; 15 \%)$, pneumologists $(\mathrm{n}=13 ; 5 \%)$, radio-oncologists $(\mathrm{n}=11 ; 4 \%)$, gastroenterologists ( $\mathrm{n}$ $=10 ; 4 \%)$, surgeons $(n=4 ; 2 \%)$ and others $(n=4 ; 2 \%)$.

Of the physicians, 233 scaled their QoL according the given numerical scale, but 22 marked intermediate values on the scale. Therefore, this scale had to be analyzed continuously and rounded to the given 11 categories.

\section{Descriptive Analysis}

The mean ( \pm standard deviation) global QoL of all participants was $6.47 \pm 1.8($ median $(M)=7)$ on the original and $6.50 \pm 1.81(\mathrm{M}$ $=7$ ) on the rounded scale, respectively. The highest mean stress levels were seen in scale 1 with $2.67 \pm 0.96$ (structural conditions), followed by scale 4 with $2.32 \pm 1.27$ (professional and private life), scale 2 with $2.30 \pm 0.85$ (stress by compassion), scale 3 with $2.04 \pm$ 0.81 (disagreeable patients), and scale 5 with $1.65 \pm 1.02$ (problems with colleagues). The mean global stress score was $2.24 \pm 0.74$.

The 5 items with the highest detected mean stress scores were 'time too short for the job I have to do' with $3.75 \pm 1.29(\mathrm{M}=4)$, 'I am so strongly engaged by my work that I cannot dedicate myself to my family/friends' with $3.51 \pm 1.50(\mathrm{M}=4)$, 'I spend too much 
Table 1. Gender-specific analysis of FBAS scales and mean stress scores; significance analyzed by Wilcoxon rank-sum test

\begin{tabular}{llllll}
\hline FBAS scale & Gender & Mean & $\begin{array}{l}\text { Standard } \\
\text { deviation }\end{array}$ & Median & Significance \\
\hline Structural conditions (1) & female & 2.84 & 0.93 & 2.85 & n.s. \\
& male & 2.59 & 0.94 & 2.70 & \\
Stress by compassion (2) & female & 2.48 & 0.83 & 2.54 & $\mathrm{p}=0.014$ \\
& male & 2.19 & 0.8 & 2.23 & \\
Disagreeable patients & female & 2.07 & 0.85 & 2.13 & n.s. \\
$\quad$ (3) & male & 2.01 & 0.77 & 2.00 & \\
Professional and private & female & 2.45 & 1.41 & 2.40 & n.s. \\
$\quad$ life (4) & male & 2.22 & 1.17 & 2.20 & \\
Problems with colleagues & female & 1.84 & 0.96 & 1.83 & $\mathrm{p}=0.022$ \\
$\quad$ (5) & male & 1.54 & 0.94 & 1.33 & \\
Total stress score & female & 2.39 & 0.76 & 2.44 & $\mathrm{p}=0.041$ \\
& male & 2.16 & 0.69 & 2.19 & \\
\hline
\end{tabular}

FBAS = Stress questionnaire of physicians and nurses (Fragebogen zur Belastung von Ärzten und Schwestern) time on paperwork' with $3.37 \pm 1.33(\mathrm{M}=4)$, 'telephone is ringing too often' with $3.25 \pm 1.53(\mathrm{M}=4)$ and 'too short of time to commit myself to personal problems of my patients' with $2.96 \pm 1.49$ $(\mathrm{M}=3)$.

\section{Analysis by Gender}

The global QoL scale showed significant differences between male and female participants on analyzing the original $(p=0.020$, Wilcoxon rank-sum test) and the rounded QoL scale $(\mathrm{p}=0.022)$ : global QoL value for women was 6.16 (rounded: 6.20), for men 6.70 (rounded: 6.70 ), respectively.

No significant differences were seen for scale 1 (structural conditions), scale 3 (disagreeable patients), scale 4 (professional and private life). The values for scale 2 (stress by compassion) were significantly higher for female physicians (mean $=2.48$ ) than for males $($ mean $=2.19 ; \mathrm{p}=0.014$ ) and for scale 5 (problems with colleagues; female $_{\text {mean }}=1.84 ;$ male $\left._{\text {mean }}=1.54 ; \mathrm{p}=0.022\right)$ and the total stress scale $\left(\right.$ scale $1-5 ;$ female $_{\text {mean }}=2.39 ;$ male $_{\text {mean }}=2.16 ; \mathrm{p}=0.041$; table 1).

\section{Analysis by Age}

The original and rounded global QoL score presented no significant differences between the 4 age groups in contrast to the FBAS scales. Scale 1 (structural conditions) resulted in significantly higher stress scores for those aged $30-50$ years (30-40 and $41-50$ years compared with $>50$ years; $\mathrm{p}<0.001$, respectively). The evaluation of scale 2 (stress by compassion) presented consistent results, with significantly increased stress scores for the younger groups ( $<30$ and $30-40$ years compared with $>50$ years; $\mathrm{p}=0.005$ in both comparisons).

Scale 3 (disagreeable patients) did not show any significant differences with regard to age. For scale 4 (professional and private life) the highest mean stress score was seen in participants of age $30-40$ years, with decreasing stress score levels as age increased (30-40 and 41-50 years compared with $>50$ years; $\mathrm{p}=0.005$ and $\mathrm{p}=0.002$, respectively).
Scale 5 (problems with colleagues) showed similar significant results (30-40 and 41-50 years compared with > 50 years; $\mathrm{p}<0.001$, respectively) with the lowest stress-score levels for age $>50$ years $($ mean $=1.36)$. The total stress score in the group $>50$ years represented the lowest stress-score levels $($ mean $=2.06)$. The comparison of the groups $<30$ or $30-40$ years with participants aged $>50$ years was statistically significantly lower for the latter $(\mathrm{p}<0.001$, respectively). The results are summarized in table 2 .

\section{Analysis by Subject}

No statistical significant differences were identified between the oncological subjects.

\section{Analysis by Working Situation}

There were no differences detected in global QoL scales between oncologists working in a clinic or in other situations. However, the mean stress score of scale 1 (structural conditions) reported a significant higher value for physicians employed in a clinic compared to those in a doctor's office $(2.80$ vs. $2.13 ; \mathrm{p}<0.001)$. A similar result was seen for scale 2 (stress by compassion) with a mean score value of 2.39 in a clinic versus 1.91 in a doctor's office $(\mathrm{p}<0.001)$, scale 4 (professional and private life) with 2.43 versus 1.79 $(\mathrm{p}=0.003)$, and scale 5 (problems with colleagues) with 1.79 versus 1.02 ( $\mathrm{p}<0.001)$. The global stress score was also different between clinic and doctor's office (2.34 vs. $1.83 ; \mathrm{p}<0.001)$.

\section{Analysis by Qualification Status}

The qualification status had no implications on global QoL scales in this survey. In all FBAS scales the medical assistants achieved significantly higher stress levels than the medical specialists.

\section{Analysis by Groups and Multivariate Analysis}

The investigation of gender and age in groups showed significantly higher mean stress values for younger females (30-40 vs. $41-50$ years: $p<0.001 ; 30-40$ vs. $>50$ years: $p=0.001)$ in scale 1 
Table 2. Analysis by age and FBAS scores; significance analyzed by Wilcoxon rank-sum test

\begin{tabular}{|c|c|c|c|c|c|}
\hline FBAS scale & Age, years & Mean & $\begin{array}{l}\text { Standard } \\
\text { deviation }\end{array}$ & Median & Significance \\
\hline \multirow{4}{*}{$\begin{array}{l}\text { Structural conditions } \\
\text { (1) }\end{array}$} & $<30(\mathrm{~A})$ & 2.92 & 0.91 & 2.80 & n.s. \\
\hline & $30-40$ (B) & 3.12 & 0.85 & 3.10 & $\begin{array}{l}\text { B/C: } p<0.001 \\
\text { B/D: } p<0.001\end{array}$ \\
\hline & $41-50$ (C) & 2.55 & 0.90 & 2.50 & n.s. \\
\hline & $>50(\mathrm{D})$ & 2.38 & 0.98 & 2.50 & n.s. \\
\hline \multirow[t]{4}{*}{$\begin{array}{l}\text { Stress by compassion } \\
\text { (2) }\end{array}$} & $<30(\mathrm{~A})$ & 2.74 & 0.78 & 2.69 & $\begin{array}{l}\mathrm{A} / \mathrm{C}: \mathrm{p}=0.002 \\
\mathrm{~A} / \mathrm{D}: \mathrm{p}=0.005\end{array}$ \\
\hline & $30-40(\mathrm{~B})$ & 2.53 & 0.90 & 2.65 & $\begin{array}{l}\text { B/C: } p=0.004 \\
\text { B/D: } p=0.013\end{array}$ \\
\hline & $41-50(\mathrm{C})$ & 2.13 & 0.76 & 2.12 & n.s. \\
\hline & $>50(\mathrm{D})$ & 2.16 & 0.84 & 2.08 & n.s. \\
\hline \multirow{4}{*}{$\begin{array}{l}\text { Disagreeable patients } \\
\text { (3) }\end{array}$} & $<30(\mathrm{~A})$ & 2.30 & 0.69 & 2.20 & n.s. \\
\hline & $30-40(\mathrm{~B})$ & 2.22 & 0.84 & 2.25 & n.s. \\
\hline & $41-50(\mathrm{C})$ & 1.90 & 0.74 & 1.88 & n.s. \\
\hline & $>50(\mathrm{D})$ & 2.05 & 0.87 & 2.00 & n.s. \\
\hline \multirow{4}{*}{$\begin{array}{l}\text { Professional and } \\
\text { private life (4) }\end{array}$} & $<30(\mathrm{~A})$ & 2.57 & 1.27 & 2.60 & n.s. \\
\hline & $30-40$ (B) & 2.78 & 1.40 & 3.00 & $\begin{array}{l}\text { B/C: } p=0.005 \\
\text { B/D: } p=0.002\end{array}$ \\
\hline & $41-50(\mathrm{C})$ & 2.19 & 1.11 & 2.10 & n.s. \\
\hline & $>50(\mathrm{D})$ & 2.01 & 1.22 & 2.20 & n.s. \\
\hline \multirow{4}{*}{$\begin{array}{l}\text { Problems with } \\
\quad \text { colleagues (5) }\end{array}$} & $<30(\mathrm{~A})$ & 1.73 & 0.99 & 1.42 & n.s. \\
\hline & $30-40$ (B) & 2.10 & 0.98 & 2.17 & $\begin{array}{l}\text { B/C: } p<0.001 \\
\text { B/D: } p<0.001\end{array}$ \\
\hline & $41-50(\mathrm{C})$ & 1.56 & 0.96 & 1.33 & n.s. \\
\hline & $>50(\mathrm{D})$ & 1.36 & 0.96 & 1.17 & n.s. \\
\hline \multirow[t]{4}{*}{ Total stress score } & $<30(\mathrm{~A})$ & 2.53 & 0.69 & 2.46 & $\mathrm{~A} / \mathrm{D}: \mathrm{p}=0.015$ \\
\hline & $30-40$ (B) & 2.58 & 0.70 & 2.54 & $\begin{array}{l}\text { B/C: } \mathrm{p}<0.001 \\
\text { B/D: } p<0.001\end{array}$ \\
\hline & $41-50(\mathrm{C})$ & 2.11 & 0.66 & 2.08 & n.s. \\
\hline & $>50(\mathrm{D})$ & 2.06 & 0.77 & 2.07 & n.s. \\
\hline
\end{tabular}

(structural conditions) and in the comparison of younger females (30-40 years) with elder males ( $41-50$ years: $p<0.001$; $>50$ years: $\mathrm{p}<0.001$, respectively). In scale 2 (stress by compassion) the younger females (30-40 years) declared significantly higher stress levels than elder males (41-50 years: $p<0.001$; $>50$ years: $\mathrm{p}<0.001)$ and elder females (41-50 years: $\mathrm{p}<0.001)$. Comparable results were found for scale 4 (professional and private life) with significantly more stress specified by younger females (3040 years) than elder males (41-50 years: $\mathrm{p}<0.001$; $>50$ years: $\mathrm{p}<0.001$, respectively) or females $(41-50$ years; $\mathrm{p}<0.001)$. For scale 5 (problems with colleagues) younger females (30-40 years) indicated higher stress values than elder females (41-50 years: $\mathrm{p}<0.001$; $>50$ years: $\mathrm{p}<0.001)$ or elder males $(41-50$ years: $\mathrm{p}<0.001$; $>50$ years: $\mathrm{p}<0.001)$. Finally, the global stress score of younger females (30-40 years) was significantly higher than in elder males $(41-50$ years: $\mathrm{p}<0.001$; $>50$ years: $\mathrm{p}<0.001)$ or elder females $(41-50$ years: $\mathrm{p}<0.001)$.

The analysis of gender and working situation illustrated a few significant differences: males in a doctor's office had lower stress scores than females in a clinic for scale 1 (structural conditions; $\mathrm{p}<0.001$ ), scale 2 (stress by compassion; $\mathrm{p}<0.001$ ), and scale 5 (problems with colleagues; $\mathrm{p}<0.001$ ). Additionally, males in a clinic showed higher stress values than in a doctor's office for scale 5 ( $\mathrm{p}<0.001)$. Investigating the global stress score, only the female stress scores in a clinic was significantly higher than in males in a doctor's office $(\mathrm{p}<0.001)$.

As expected, the logistic regression model showed the variable age as a confounder for the qualification status. A weak influence might be given by gender with a $\mathrm{p}$ value of 0.091 in the $\chi^{2}$-test for the maximum likelihood estimate. To examine the influence of gender, age, medical subject, and working situation on qualification status univariate analysis was performed. With exception of gender, the results of the other 3 variables might be influenced by missing data (for example, no oncological specialist with age $<30$ years) and therefore overexpress significance. Thus, by this analysis qualification status was especially influenced by gender $(\mathrm{p}<0.001)$.

For the multivariate analysis for the variable qualification status the age group was excluded. The model was performed with the parameters gender, working situation, medical subject, and global stress score. This model described the dependence of the 3 variables: gender $(p=0.0045)$, working situation $(p=0.0317)$ and global stress score $(p=0.0008)$; the Hosmer-Lemeshow test with $\mathrm{p}=0.472$ showed a fair fitting behavior. 


\section{Discussion}

The main results of this current survey among German oncologists were the confirmation of 'structural conditions' as an important stress factor, secondly, the evidence of gender-specific differences in job stress, and finally the indication of more job stress among young physicians.

The strongest stress factor identified in our survey was 'structural conditions' without any difference in the analyzed subgroups. 4 out of the 5 items with the highest detected stress scores were part of scale 1 , and identified time pressure and overload with paperwork.

Similarly, Ramirez found work overload, organization responsibilities and conflicts as source of professional dissatisfaction and burnout [13] in the early survey among UK non-surgical oncologists. The QoL work group of the German Society for Radio-Oncology (DEGRO) confirmed these stress factors in a multi-center analysis of German and Austrian departments of radiotherapy among physicians, physicists, nurses, and radiographers [14]. The 'structural conditions' of the FBAS score showed the highest stress levels in nurses (mean FBAS total score 2.2) and physicians (2.1) with significantly lower levels of job stress $(\mathrm{p}<0.001)$ in radiographers (1.7) and physicists (1.0).

This result is in contrast to the survey of the Spanish Society of Medical Oncology [15], which showed the perception of time pressure and social deterioration to be responsible for high burnout levels. Shanafelt et al. [16] found that, among the North Central Cancer Treatment Group (NCCTG) for medical oncologists, 'patient load', followed by 'balancing personal and professional life' and 'dealing with death/suffering of patients' were the main stressors. Structural conditions such as 'administrative duties' were not as important in causing high stress levels for members in NCCTG, as seen in our survey. The importance of balancing private and professional life was confirmed by the NCCTG and by our study.

However, the actual focus on 'structural conditions' as the main stressor in the oncological work environment was not present in 1 of the first analyses of the last century: the random survey among 1,000 subscribers to the Journal of Clinical Oncology (JCO) in 1990 pointed out insufficient personal and/or vacation time, continuous exposure to fatal illness, and frustration with limited therapeutic success as main reasons for burnout syndrome among oncologists [1]. The findings of newer analyses and the current study indicate that job stress in the oncological work environment may be influenced by patients' fatal illness and compassion, but is mainly determined by structural conditions that may have changed since the early 1990s. In particular, the German health system is confronted with a significant reduction in hospital beds in general and in oncology with a shift towards outpatient care [17]. Coevally, general mean time of hospitalization in Germany has been reduced almost by half [17]. The resulting work concentration is also present in the oncological setting. The accompanying structural changes may, therefore, explain the stress factors found in our study, and supports the distinctions between oncologists employed in clinics and doctor's offices. In the subgroup analysis, significantly lower stress levels were detected in global stress scale and in 'structural condi- tions' for oncologists working in a doctor's office compared to clinical oncologists.

In addition to these identified stress factors, significant genderspecific differences were found in the current study. Female physicians rated a lower global QoL than males and a higher total stress score in the FBAS questionnaire. For the FBAS scales 'stress by compassion' and 'problems with colleagues', women reported significantly higher stress values than male colleagues. An explanation for this difference might be the higher frequency of younger female assistant participants (58.0\% vs. $42.0 \%$ male assistants) compared to older male senior oncologists (70.9\% vs $29.1 \%$ female senior oncologists), which may be caused by the fact that women reaching the step of medical specialization or functional position have to face, besides their job stress, also that as a mother. This everyday challenge for female oncologists of $<50$ years could be accompanied by a lower rate of qualification status and congress participations. Noteworthy, no gender difference in scale 4 'professional/ private life' was found. Up to now only rare information has been available about gender-specific differences with regards to job stress among physicians.

Compared to our findings, the DEGRO survey [14] identified only female gender in univariate analysis as a risk factor for job stress in scale 2 'stress by compassion' $(\mathrm{p}=0.038)$. In that study there were more female participants $(73.6 \%)$ and radiographers, nurses, and other non-physicians rated scale 2 with higher stress levels than the physicians. Due to inter-professional differences these results cannot be considered as specific for female physicians. Also, in the DEGRO study, scale 4 'professional/private life' showed more job stress for males ( $\mathrm{p}=0.006)$, and scale 5 'problems with colleagues' for participants of $<50$ years $(p=0.024)$. The current study confirms global stress as a parameter dependent on gender, professional status and working condition.

Kuerer et al. [18] pointed out that women were more likely to meet the criteria for burnout ( $36.8 \%$ vs. $26.1 \% ; \mathrm{p}=0.029$ ) and show a lower mental QoL $(p=0.001)$. In this report, potential sources of increased female job stress and burnout were suggested to be the minor part played by women among a male-dominated surgery and surgical subspecialties, as well as professional dissatisfaction and the multiple role conflict due to child care. By contrast, in the NCCTG, Shanafelt et al. [16] observed no significant differences in job stress, but an increased rating of a lower degree of overall wellbeing among female medical oncologists $(p=0.02)$. Likewise, Buddeberg et al. [5] did not identify gender-specific discrepancies in their prospective longitudinal study focused on work stress, health, and life satisfaction in Switzerland among young doctors. By contrast, a meta-analysis by Purvanova and Muros [19] found genderspecific features among work-related burnout cases. They identified emotional exhaustion and depersonalization, and significant differences between the described effects in the United States and European Union relying on conservative or progressive labor politics. This could be a reason that women are more likely to report burnout; thus, the 'number of women suffering from emotional exhaustion relative to the number of men is more than double in the US compared to the EU' [19]. 
Finally, the present survey confirmed the results of other studies showing less QoL and more job stress among younger oncologists $[4,18-22]$. This effect may arise from multiple factors with significantly higher stress levels for oncologists of $<50$ years in structural conditions, compassion, professional and private life, and problems with colleagues (scales 1, 2, 4, and 5). In particular, the double burden for female oncologists of $<50$ years old, with full-time jobs and the duty of running the family affairs, has to be recognized. These 4 issues seem to be the central problems for younger oncologists, independent of their specialization. Despite of this statement, qualification status was influenced by gender, working situation, and age. It is noteworthy that female oncologists showed significantly more job stress in the grouped analysis by age than male oncologists in our study.

The present study has some limitations. In contrast to the usually applied Maslach Burnout Inventory, the FBAS questionnaire was used for this analysis showing more specific oncological items. However, the different tools applied make comparisons with other reports more difficult. Moreover, different socio-cultural and professional conditions and backgrounds might contribute to variation in results, reduce comparability and hinder general problem solving. The response rate of $14.5 \%$ limited interpretation but is comparable with other surveys performed randomly, and should be understood as a minor issue at the annual meeting. Finally, the survey was performed only among participants of the AIO congress and AIO members reachable by e-mail, representing a group of physicians engaged in clinical research beyond daily oncology practice, and in consequence, the results reported may not be representative.
In conclusion, the survey among the AIO members revealed a high personal and professional QoL, concurrently demonstrating that job stress is present in German oncology. 'Structural conditions' were identified as the main stress factor, and an age younger than 50 years and female gender as 'risk factors' for stress. As this study has to be rated as a pilot study additional research in warranted to elucidate the reasons for these findings (e.g. work intensification, reduction of personnel, general economic pressure from hospital management). Therefore, further studies should include more professional and specific oncological data (i.e. number of beds, specialized hemato-oncological department, and special oncological certifications like cancer centers) to allow more stratification in subgroups. Improvement of the structural conditions, i.e. the work burden and reduction of bureaucracy, should be a crucial aim not only for opinion leaders of health care politics and clinic management but also for the oncological physicians themselves. The oncological professional associations should state and quantify measures for improving the current situation. Additional research among several oncological specializations is warranted to develop evidence-based intervention strategies, which should include psychosocial or psychotherapeutic support as well as the help of colleagues with an explicit competence and approbation in improvement of QoL and coping of job stress.

\section{Disclosure Statement}

The authors declare no conflict of interest.

\section{References}

1 Whippen DA, Canellos GP: Burnout syndrome in the practice of oncology: Results of a random survey of 1,000 oncologists. J Clin Oncol 1991;9:1916-1920.

2 Bundesärztekammer, Ärztestatistik 1998-2011.

3 Taylor C, Graham J, Potts HWW, et al.: Changes in mental health of UK hospital consultants since the mid-1990s. Lancet 2005;366:742-744.

4 Glasberg J, Horiuti L, Novais MAB, et al.: Prevalence of the burnout syndrome among Brazilian medical oncologists. Rev Assoc Med Bras 2007;53:85-89.

5 Buddeberg-Fischer B, Stamm M, Buddeberg C, et al.: Work stress, health and satisfaction of life in young doctors: Results of a longitudinal study in Switzerland. Dtsch Med Wochenschr 2008;133:2441-2447.

6 Buddeberg-Fischer B, Klaghofer R, et al.:. Work stress and reduced health in young physicians: Prospective evidence from Swiss residents. Int Arch Occup Environl Health 2008;82:31-38.

7 Lim RCH, Pinto C: Work stress, satisfaction and burnout in New Zealand radiologists: Comparison of public hospital and private practice in New Zealand. J Med Imaging Radiat Oncol 2009;53:194-199.

8 Herschbach P: FBAS - Fragebogen zur Belastung von Ärzten und Schwestern, Institut für Psychosomatische Medizin, TU München 1991.
9 Herschbach P: Die psychische Belastung von Ärzten/ Ärztinnen und Krankenpflegekräften. Weinheim: Verlag Chemie Edition Medizin 1991.

10 Herschbach P: Stress im Krankenhaus - Die Belastung von Krankenpflegekräften und Ärzten/Ärztinnen. Psychother Psychosom Med Psychol 1991;5:176-186.

11 Herschbach P: Work-related stress specific to doctors and nurses on oncology wards. J Psychosoc Oncol 1992;10:79-99.

12 Herschbach P: Work-related stress specific to doctors and nurses on oncology wards. J Cancer Res Clin Oncol 1992;118(Suppl):180.

13 Ramirez AJ, Graham J, Richards MA, et al.: Burnout and psychiatric disorder among cancer clinicians. Br J Cancer 1995;71:1263-1269.

14 Sehlen S, Vordermark D, Schäfer C, et al.: Job stress and job satisfaction of physicians, radiographers, nurses and physicists working in radiotherapy: A multicenter analysis by the DEGRO Quality of Life Work Group. Radiat Oncol 2009;4:6.

15 Camps C, Escobar Y, Esteban E, et al.: Professional burnout among Spanish medical oncologists. Clin Transl Oncol 2009;11:86-90.
16 Shanafelt TD, Novotny P, Johnson ME, et al.: The wellbeing and personal wellness promotion strategies of medical oncologists in the North Central Cancer Treatment Group. Oncology 2005;68:23-32.

17 Statistisches Bundesamt (Hrsg.) Fachserie 12, Reihe 6.1.1, Grunddaten der Krankenhäuser 2011 (18.10. 2012).

18 Kuerer HM, Eberlein TJ, Pollock RE, et al.: Career satisfaction, practice patterns and burnout among surgical oncologists: Report on the quality of life of members of the Society of Surgical Oncology. Ann Surg Oncol 2007;14:3043-3053.

19 Purvanova RK, Muros JP: Gender differences in burnout: A meta-analysis. J Vocat Behav 2010;77:168-185.

20 Blanchard P, Truchot D, Albiges-Sauvin L, et al.: Prevalence and causes of burnout amongst oncology residents: A comprehensive nationwide cross-sectional study. Eur J Cancer 2010;46:2708-2715.

21 Bragard I, Dupuis G, Razavi D, et al.: Quality of work life in doctors working with cancer patients. Occup Med (Lond) 2011;62:34-40.

22 Ramondetta LM, Urbauer D, Brown AJ, et al.: Work related stress among gynecologic oncologists. Gynecol Oncol 2011;123:365-369. 